\title{
Pengintegrasian YII Framework Berbasis API pada Sistem Penilaian Absensi
}

\section{Integration of API-Based YII Framework on Attendance Assessment System}

\author{
Untung Rahardja ${ }^{1}$, Qurotul Aini ${ }^{2}$, Nuke Puji Lestari Santoso ${ }^{3}$ \\ ${ }^{1}$ Dosen Sistem Informasi STMIK Raharja ${ }^{2}$ Dosen Sistem Informasi STMIK Raharja \\ ${ }^{3}$ Mahasiswa STMIK Raharja \\ email:․ㅡㄴ
}

\begin{abstract}
Abstrak
Sistem penunjang perkuliahan pada Perguruan Tinggi memiliki informasi berupa identitas mahasiswa dalam setiap sistemnya, seperti foto profile, nama, NIM (Nomor Induk Mahasiswa) dan sebagainya sesuai dengan kebutuhan sistem. Namun, dalam website PenA (Penilaian Absensi) teridentifikasi 2 (dua) permasalahan yaitu salah satunya identitas user hanya berupa nama dan status. Untuk memudahkan Dosen pembimbing mendapatkan informasi yang akurat terhadap mahasiswa bimbingan dibutuhkan Foto profile sebagai identitas utama. Penyelesaian masalah tersebut adalah dengan adanya integrasi Google+ pada sistem PenA agar terdapat foto profile yang sama seperti Google+. Rinfo+ atau Google+ ini adalah aplikasi menggunakan platform google yang berintegrasi dengan Rinfo. Integrasi Rinfo+ dengan PenA berbasis yii framework menggunakan teknologi Application Programming Interface yang memiliki tingkat keamanan cukup baik dalam masalah keamanan serta ringan dalam mengembangkan aplikasi web. Menggunakan 7 (tujuh) metode penelitian untuk mengatasi penyelesaian tersebut. Dengan adanya integrasi ini diharapkan agar foto profile pada sistem PenA dijadikan sebagai identitas user yang lebih akurat bagi mahasiswa juga dosen pembimbing serta memberikan visual yang lebih menarik pada website PenA.
\end{abstract}

Kata kunci-PenA, Application Programming Interface, Rinfo+

\begin{abstract}
Supporting lecture system in college has information on student identity on each system, such as photo profile, name, nim (Student Identity Number) and so on according to system requirement. However, in the website PenA (Attendance Assessment) identified 2 (two) problems that one of the identity of the user only a name and status. To facilitate Lecturer guidance to get accurate information on guidance students required Photo profile as the main identity. The problem solving is with the integration of Google+ on the PenA system to have the same profile photo as Google+. Rinfo + or Google + this is an app using google platform that integrates with Rinfo. Rinfo + integration with yii framework based Pen A uses Application Programming Interface technology that has good security level in security problem and is light in developing web application. Use 7 (seven) research methods to resolve the settlement. With this integration is expected that the profile photo on the PenA system serve as a more accurate user identity for students and supervisors as well as provide a more attractive visual on PenA website.
\end{abstract}

Keywords - PenA, Application Programming Interface, Rinfo+

\section{PENDAHULUAN}

Pada zaman ini sosial media merupakan elemen yang paling menonjol dalam industri komunikasi. Dengan adanya sosial media yang berkembang pesat saat ini sangat berpengaruh 
terhadap setiap bidang kehidupan. Dimana suatu perubahan diperlukan dalam berbagai aspek misalkan bentuk penyajian informasi, sehingga informasi dapat efektif dan mudah dipahami [1]. Terlebih lagi sosial media kini dapat digunakan dalam berbagai bidang seperti perkuliahan, pendidikan, dan lain-lainnya. Seiring berkembangnya sosial media, kini teknologi web juga banyak dimanfaatkan sebagai sistem informasi[2]. Didukungnya DSM sebagai dashboard pengdukung upaya peningkatan mutu suatu sistem informasi [3].

Perkembangan yang ada pada bidang teknologi kini ikut serta mempengaruhi Perguruan Tinggi dalam kegiatan akademik. Salah satunya dengan mengukur kinerja organisasi atau Perguruan Tinggi dalam hal meningkatkan kuliatas [4]. Tentunya sebuah Perguruan Tinggi memiliki beberapa kegiatan akademik contohnya kegiatan dalam pembelajaran atau bimbingan. Perguruan Tinggi Raharja memiliki email khusus bagi Pribadi Raharja yang platform nya sama seperti Gmail yang disebut email Rinfo. Rinfo atau biasa disebut email Raharja.info adalah bagian dari Tpi (Ten pilar IT learning) sebagai alat komunikasi berupa email resmi bagi pribadi raharja, maupun dosen juga staf. [5]. Namun, Rinfo dengan Gmail tetap memiliki perbedaan, yaitu Gmail menggunakan Gmail.com sebagai domain email nya, maka Rinfo menggunakan raharja.info sebagai domain email nya. Dari perbedaan yang telah dijabarkan, namun keduanya tetap memiliki fungsi yang tidak jauh berbeda [6]. Dan penggunaan Rinfo sudah meluas ke seluruh civitas akademika dalam hal kegiatan akademik yang memudahkan Pribadi Raharja untuk berkomunikasi. Adanya penambahan tools aplikasi dalam Rinfo yang terintegritas secara langsung dengan Rinfo yaitu Rinfo+.

Rinfo+ atau Rinfo Plus adalah salah satu media yang dioperasikan oleh Google Inc [7]. Sehingga Rinfo+ dapat menunjang kebutuhan bagi Pribadi Raharja dalam perkuliahan. Di dalam Rinfo+ terdapat profile, di mana profile dapat dijadikan sebuah identitas bagi pengguna Rinfo tersebut.

Sebagai kampus yang berjalan dalam bidang teknologi informasi Perguruan Tinggi Raharja memiliki website resmi dalam sistem penilaian absensi secara online. Sistem PenA (Penilaian Absensi) merupakan sebuah sistem penilaian absensi secara online di Perguruan Tinggi Raharja untuk memberikan informasi secara real dalam perkuliahan. Sistem penA (Penilaian Absensi) yang sudah menggunakan SSO (Single Sign On/Out) yaitu dapat Login hanya dengan menggunakan Rinfo sebagai Magic Key [8]. Single-sign-on atau SSO adalah teknologi yang mengizinkan pengguna jaringan agar dapat mengakses sumber daya dalam jaringan hanya dengan menggunakan satu akun pengguna saja. Dengan SSO, pengguna cukup dengan melakukan proses autentifikasi sekali saja untuk mendapatkan izin akses kepada semua layanan yang terdapat di dalam jaringan [9] .

Application Programming Interface atau API adalah sebuah dokumentasi yang terdiri dari interface, kelas, fungsi, struktur dan sebagainya agar dapat membangun sebuah perangkat lunak. Dan API bisa dikatakan sebagai suatu kode pemrograman penghubung antara aplikasi atau web yang telah kita buat dengan fungsi yang dikerjakan [10]. Google+ api merupakan pemrograman yang menghubungkan ke Google+ [11]. Artinya dengan API, web PenA (Penilaian Absensi) akan terintegrasi dengan Rinfo+. Yang akan menghubungkan foto profile pada Rinfo+ dalam sistem PenA (Penilaian Absensi) . Dalam hal ini Google Api sebagai kode pemrograman yang disederhanakan yang dapat ditambahkan oleh sistem PenA (Penilaian Absensi) untuk mengakses dan terintegrasi dengan fitur Rinfo+.

Dalam sistem informasi dirancang untuk saling terintegrasi semakin dibutuhkan beriringan dengan berkembangnya waktu. Integrasi data merupakan proses penggabungan data dari beberapa sumber ke dalam bentuk yang terintegrasi. Sumber integrasi data bisa menghasilkan jawaban terhadap permintaan yang tak dapat dijawab oleh masing-masing sumber data apabila dilakukan secara terpisah [12]. Dalam rekayasa teknologi, penggunaan yang sama namun berbeda elemen dapat di integrasikan guna melihat keefektifan [13]. Adanya sebuah inovasi baru yaitu, Sistem PenA (Penilaian Absensi) yang integrasi dengan Rinfo+ akan 
memberikan efektivitas dan keakuratan informasi kepada Pribadi Raharja. Yang dimaksud dengan terintegrasi antar keduanya yaitu Foto Profile mahasiswa bimbingan pada PenA (Penilaian Absensi) akan sama dengan Rinfo+. Maka foto profile mahasiswa bimbingan Pribadi Raharja yang ada dalam Rinfo+ secara otomatis akan berubah dalam sistem PenA (Penilaian Absensi) apabila foto profile pada Rinfo+ diubah. Hal ini bertujuan agar foto profile yang dipasang akan lebih akurat dan efektif serta membantu Pribadi Raharja memiliki informasi yang akurat bagi Dosen Pembimbing. Selain itu tanpa adanya foto profile mahasiswa bimbingan dalam absensi online tidak akan berhasil.

Mengenai penelitian yang sudah dilakukan perihal terintegrasinya jaringan sosial. Dalam mengembangkan sistem PenA (Penilaian Absensi) yang terintegrasi dengan Rinfo+ ini menggunakan 6 (enam) tinjauan pustaka tentang penelitian terdahulu sebagai pedoman dalam pengembangan ini, yaitu : Penelitian mengenai Integrasi Data Karya Ilmiah pada Website Widuri Raharja.Info ke dalam Website Raharja.ac.id. Penelitian ini dijelaskan mengenai mengintegrasikan data karya ilmiah terhadap website widuri.raharja.info ke dalam raharja.ac.id, sehingga jika adanya perubahan data yang ada di dalam widuri akan secara otomatis berubah dalam website raharja.ac.id [14]. Penelitian selanjutnya sistem pelacakan posisi kendaraan dengan teknologi GPS \& GPRS berbasis web. Membahas sistem pelacakan kendaraan menggunakan teknologi GPS dengan komunikasi GPRS memanfaatkan Google Maps API dengan javascript. Dari database "tracking" diambil menggunakan pemrograman PHP dan di integrasikan dengan Google API sehingga dapat ditampilkan pada Google Maps yang bisa di akses melalui web [15].

Selanjutnya penelitian mengenai "Integrasi Teknologi Google Earth dan Flash dalam penyajian Sistem Informasi Sekolah SMA dan SMK di Kota Salatiga. Penelitian ini membahas tentang integrasi Google Earth memberikan informasi mengenai profile sekolah dengan citra satelit yaitu gambar tampak atas, dan flash panorama berupa gambaran sekolah yang divisualisasikan yang dapat melihat keadaan sekolah, kelas, dan fasilitas sekolah. Serta memberikan informasi bagi orang tua siswa maupun calon siswa sebagai pembanding sekolah SMA dan SMK di Kota Salatiga. Dalam merancang sistem ini menggunakan UML (Unified Modelling Language) dan pembuatan animasi flash panorama dengan menggunakan Adobe Flash CS 3[16]. Selain itu penelitian "Aplikasi Rangkaian sosial Google Plus dalam pengajaran dan pembelajaran komponen sastera" menjelaskan bahwa Google Plus merupakan sebagian dari teknik dan aturan yang digunakan dalam memajukan pendidikan tanpa rasa ragu sedikit pun bagi guru-guru Bahasa Melayu. Dengan adanya konsep sosial media memiliki tujuan lebih baik dan memberi manfaat selain bersosialisasi guru dijadikan sebagai moderator untuk bertukar pikiran [17].

Penelitian lainnya tentang pemanfaatan Google Api untuk model interoperability web berbasis PHP dengan Google Drive. Penelitian ini membahas pemanfaatan Google Drive Api dalam menunjang model interoperability dari sistem yang ada menggunakan tool UML (Unified Modelling Language) dan API Google Drive sebagai sistem implementasinya [18].

Adapun penelitian yang dilakukan oleh Untung Rahardja, Suryo Guritno, dan Valent Setiatmi mengenail "Access Restriction sebagai bentuk pengamanan dengan metode IP Token" membahas integritas dan keamanan data agar data yang tersimpan tidak hilang atau rusak dengan menggunakan IP Token. Dan adanya integrasi tersebut menampilkan keseluruhan informasi terhadap user dimanapun dan kapanpun tanpa batas akses masuk [19].

Berdasarkan dari penelitian di atas beberapa penelitian mengenai integritas. Namun bisa disimpulkan bahwa belum adanya penelitian secara khusus mengenai pembahasan integrasi foto profile antara jaringan sosial (Rinfo+) dengan sistem website (Penilaian Absensi/PenA) yang menggunakan Yii Framework. 


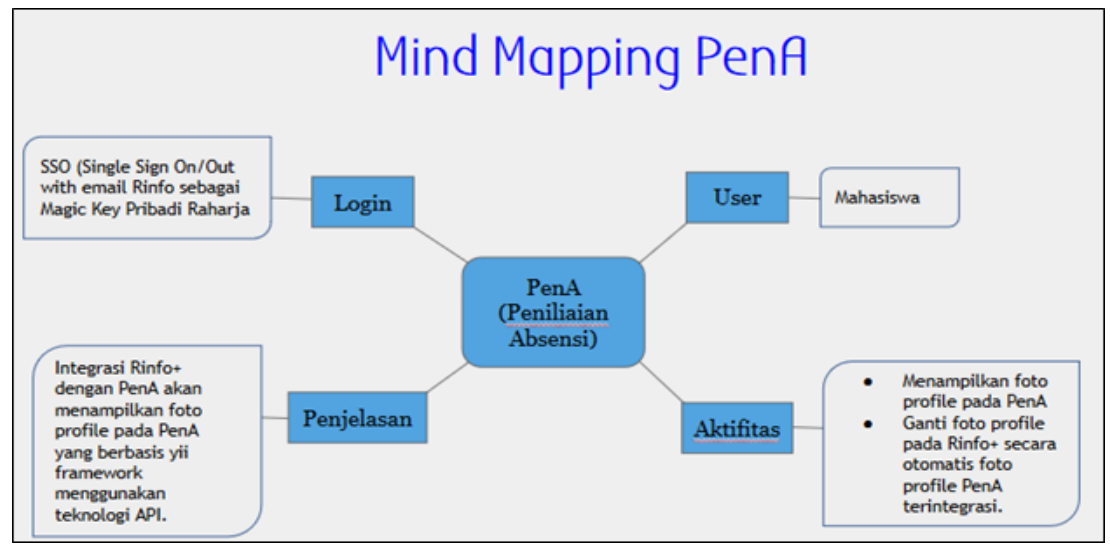

Gambar 1. Mind Mapping PenA (Penilaian Absensi)

Gambar 1 di atas merupakan Mind Mapping atau gambaran pemetaan pikiran yang menjelaskan sketsa tentang PenA (Penilaian Absensi) yang sudah terintegrasi dengan Rinfo+. Adapun penjelasan dari mind mapping tersebut yaitu, (1) menjelaskan bahwa integrasi Rinfo+ dengan PenA (Penilaian Absensi) yang berbasis yii framework menggunakan teknologi Google API guna memberikan identitas bagi mahasiswa/Pribadi Raharja tersebut. (2) Aktivitas dalam PenA (Penilaian Absensi) yaitu menampilkan foto profile dalam website PenA (Penilaian Absensi) pada navigation bar dan header, yang sudah terintegrasi dengan Rinfo+ jika foto profile pada Rinfo+ terganti. (3) User yang terdapat dalam PenA (Penilaian Absensi) yang sudah terintegrasi dengan Rinfo+ yaitu Mahasiswa. (4) Sistem PenA (Penilaian Absensi) sudah dapat Login dengan SSO (Single Sign On/Out) with Rinfo yang dimiliki Pribadi Raharja sebagai Magic Key.

Perancangan sistem PenA (Penilaian Absensi) yang terintegrasi dengan Rinfo+ menggunakan Yii framework. Yii framework merupakan pemrograman secara luas dalam perkembangan aplikasi web [20]. Dengan mengimplementasikan sebuah pola desain model view controller (MVC). MVC ini bertujuan dalam hal memisahkan logika bisnis tiap pertimbangan antarmuka bagi pengguna agar memudahkan para pengembang dalam merubah setiap bagian tanpa mempengaruhi yang lainnya [21]. Selain itu, Yii juga memperkenalkan Application atau front controller (controller depan), sebagai enkapsulasi konteks eksekusi guna memproses sebuah request. Application juga mengumpulkan sebagian informasi perihal request pengguna kemudian mengirim ke controller yang sesuai dengan PenA (Penilaian Absensi) tahap penanganan selanjutnya [22].

\section{METODE PENELITIAN}

Dalam penelitian ini sebuah sistem yang dirancang diperlukan metode penelitian untuk mengatasi masalah yang ada di atas. Dalam penelitian ini menggunakan metode penelitian yaitu Merumuskan masalah, Merancang penelitian, Mengumpulkan Data, Mengolah Data, Menyajikan Data, Analisis Data dan Laporan Penelitian. 


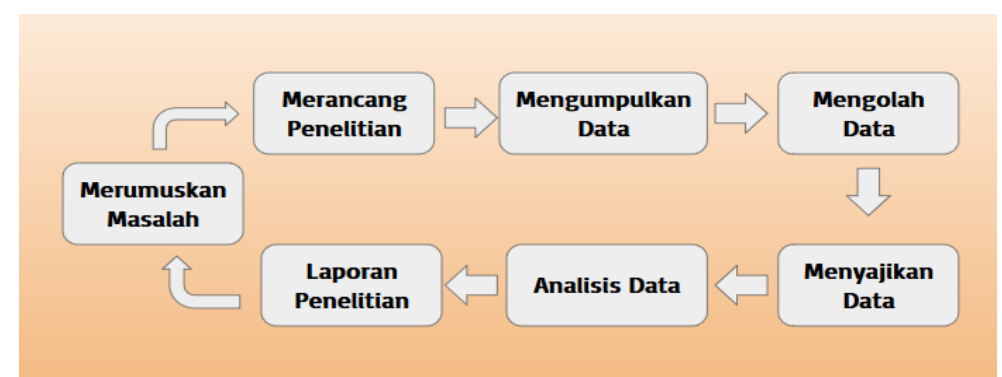

Gambar 2. Metode Penelitian

Berikut terdapat 7 (tujuh) keterangan dalam metode penelitian sebagai berikut:

1. Merumuskan masalah

Dalam merumuskan masalah kita perlu melakukan observasi agar dapat mengetahui latar belakang permasalahan apa yang terjadi pada sistem PenA (Penilaian Absensi) sebelumnya yang sudah berjalan.

2. Merancang Penelitian

Merancang sebuah konsep sistem PenA (Penilaian Absensi) ke dalam bentuk prototype agar memudahkan pemahaman saat menerapkan dalam website yang berbasis Yii Framework dan pemrograman PHP dengan teknologi Google APIs.

3. Mengumpulkan Data

Mempersiapkan data yang diperlukan dalam merancang PenA (Penilaian Absensi) seperti Rinfo Pribadi Raharja.

4. Mengolah Data

Melakukan integrasi antara Rinfo+ dengan sistem PenA (Penilaian Absensi) untuk mendukung koneksi foto profile dalam PenA (Penilaian Absensi).

5. Menyajikan Data

Apabila data tersebut sudah diolah akan ditampilkannya sebuah informasi yang berguna bagi Pribadi Raharja. Dimana informasi yang disajikan haruslah jelas dan dapat dipahami.

6. Analisis data

Melakukan analisa dari hasil proses awal merumuskan masalah yang ada.

7. Laporan Penelitian

Membuat laporan hasil dari seluruh penelitian secara detail yang pada akhirnya permasalahan tersebut terselesaikan dengan baik.

\section{HASIL DAN PEMBAHASAN}

Dalam bagian ini akan dibahas mengenai analisa yang dibutuhkan oleh sistem yang dirancang. Berdasarkan dari permasalahan di atas akan dibutuhkan perancangan sistem, rancangan antarmuka sistem, dan rancangan interface sistem pada web berbasis Yii Framework . Selanjutnya implementasi sebuah sistem dan menampilkan screenshoot pada sistem PenA (Penilaian Absensi) yang sudah terintegrasi dengan Rinfo+.

3.1 Analisa Permasalahan

Sistem PenA (Penilaian Absensi) yang ada di Perguruan Tinggi Raharja sudah menggunakan Login SSO (Single Sign On/Out) dengan Magic Key yaitu email Rinfo. Namun saat masuk ke dalam home PenA (Penilaian Absensi) hanya terdapat nama dan status Pribadi Raharja saja yang menjadi informasi bagi mahasiswa tersebut. Hal ini memberikan tampilan secara visual yang kurang menarik karena tidak terdapat foto profile. Selain itu, jika tidak adanya foto profile maka sistem PenA (Penilaian Absensi) tidak berjalan karena tidak terdeteksinya mahasiswa bimbingan tersebut. 


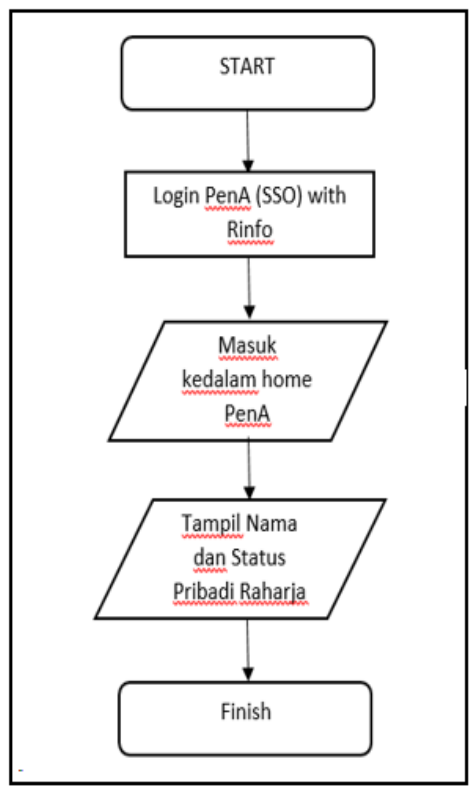

Gambar 3. Flowchart Sistem PenA yang berjalan

Gambar di atas menjelaskan mengenai sistem PenA (Penilaian Absensi) yang berjalan jika masuk ke dalam home penA (Penilaian Absensi) hanya ada informasi bagi mahasiswa tersebut berupa nama dan status Pribadi Raharja saja.

\subsection{Pemecahan Permasalahan}

Dari penjelasan permasalahan pada flowchart sistem PenA (Penilaian Absensi) di atas dapat meminimalisir permasalahan yaitu integrasi sistem PenA (Penilaian Absensi) dan Rinfo+ dengan menggunakan Google Api. Dengan adanya integrasi tersebut dalam sistem PenA (Penilaian Absensi) akan terdapat foto profile sebagai identitas mahasiswa Pribadi Raharja dan bisa melakukan login pada PenA (Penilaian Absensi).

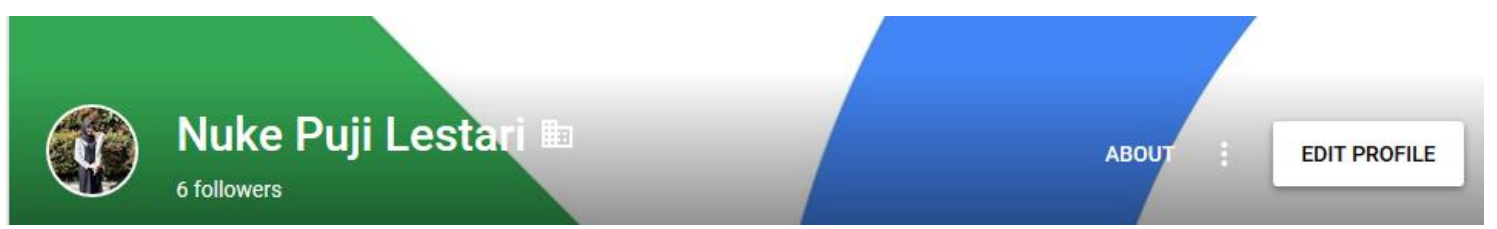

Gambar 4. Foto Profile pada Rinfo+

Dengan adanya integrasi sistem PenA (Penilaian Absensi) dan Rinfo+ menggunakan Google Api akan meminimalisir masalah yang ada, guna menampilkan foto profile mahasiswa bimbingan pada PenA (Penilaian Absensi) juga saat scanning Qrcode berhasil sebagai identitas mahasiswa. 


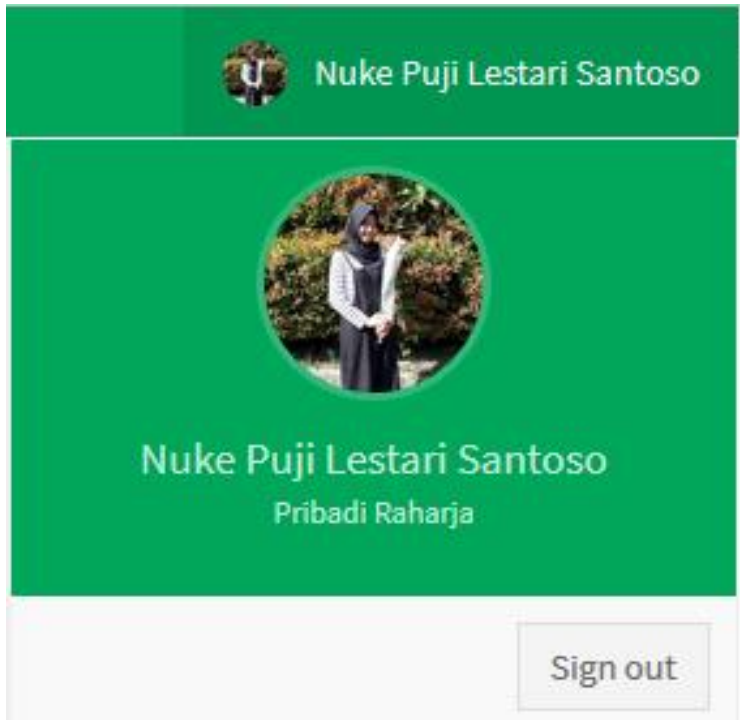

Gambar 5. Foto Profile pada sistem PenA

Dari gambar 5 merupakan foto profile mahasiswa bimbingan pada sistem PenA (Penilaian Absensi) yang sudah terintegrasi dengan Rinfo+. Di mana foto profile mahasiswa bimbingan PenA (Penilaian Absensi) akan sesuai dengan Rinfo+ yang digunakan sebagai identitas mahasiswa Pribadi Raharja.

Dengan di implementasinya integrasi Rinfo+ dengan sistem PenA (Penilaian Absensi) maka dapat memberikan manfaat yang sangat signifikan bagi mahasiswa bimbingan dan pembimbing dalam melihat rekap absensi mahasiswa bimbingan. Selain itu, mahasiswa bimbingan dapat mengetahui status jika mahasiswa tersebut sudah login dengan ditandai adanya foto profile pada navigation bar dan header pada sistem PenA (Penilaian Absensi).

\subsection{Cara integrasi Rinfo+ dan PenA (Penilaian Absensi)}

Google+ Api adalah pemrograman yang terhubung ke Google+ [11]. Google+ Api ini digunakan untuk mengintegrasikan sistem web PenA (Penilaian Absensi) dengan Google+. Integrasi ini memungkinkan terhubungnya PenA (Penilaian Absensi) dengan Google+ secara maksimal. Untuk memanggil API tersebut diperlukan OAuth 2.0 atau kunci API agar dapat mengakses platform Google+ secara terprogram dan seluruh layanan yang ada di Google [23].

Tahapan awal yang dilakukan untuk integrasi sistem PenA (Penilaian Absensi) dan Rinfo+ yaitu membuat project baru pada console.developer.google.com. Nama project ini digunakan untuk meminta hak akses email dan profile pada Rinfo untuk dintegrasikan ke PenA (Penilaian Absensi). Setelah create project akan tampil Client ID dan Client secret secara otomatis atau Autogenerate. Client ID dan Client secret ini akan digunakan untuk Login SSO (Single Sign On/Out) pada PenA (Penilaian Absensi). Mengaktifkan/ enable Google+ Api yang sudah dibuat pada console.developer.google.com menggunakan keywoard 'Google+ API' [21]. 


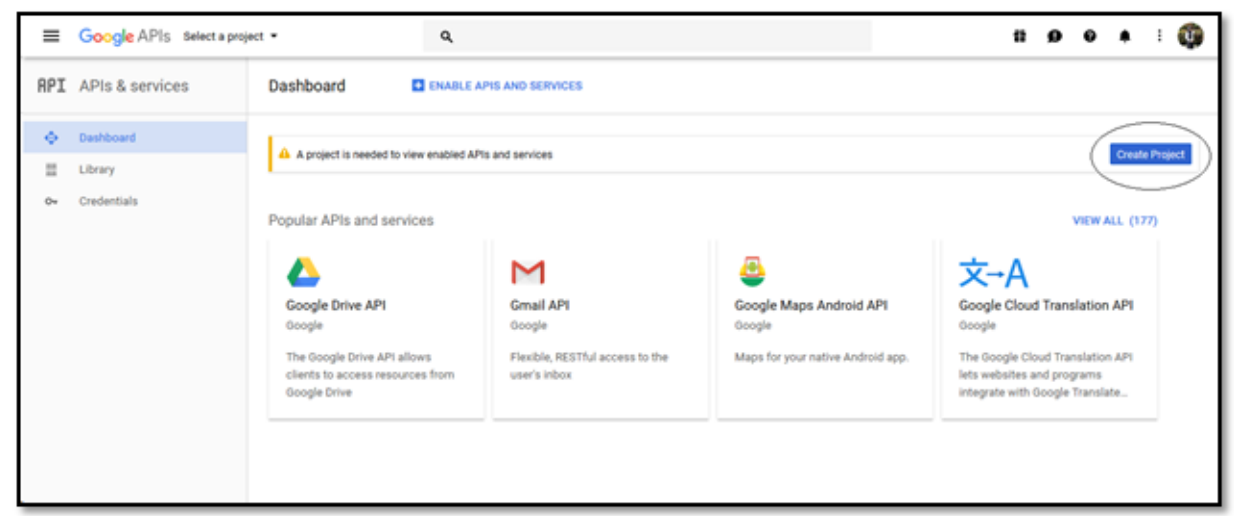

Gambar 6. Create Project pada dashboard console.developer.google.com

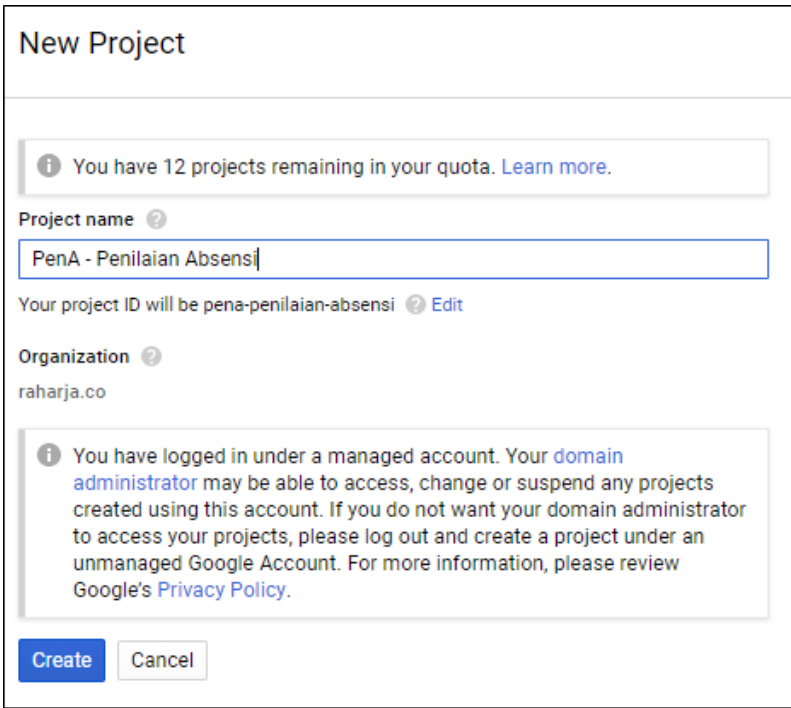

Gambar 7. Membuat nama project yang diperlukan

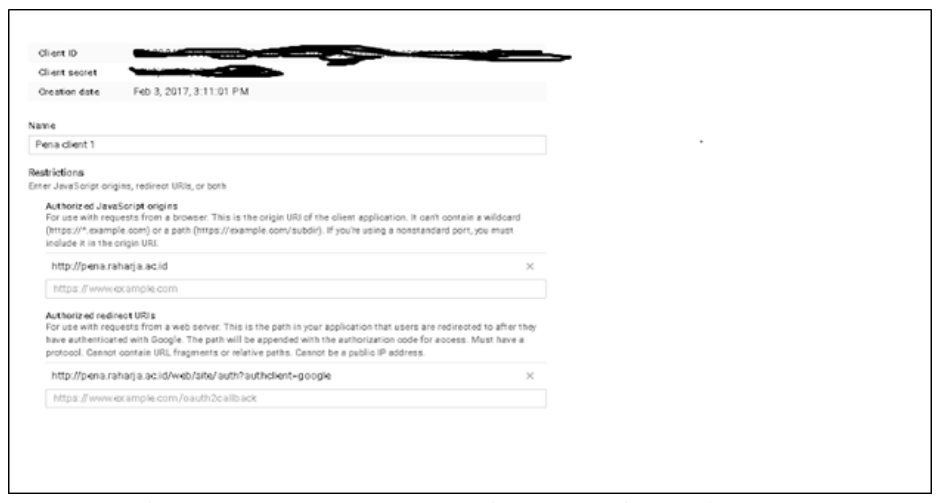

Gambar 8. Autogenerate Client ID dan Client secret 
Pengintegrasian YII Framework Berbasis API pada ...

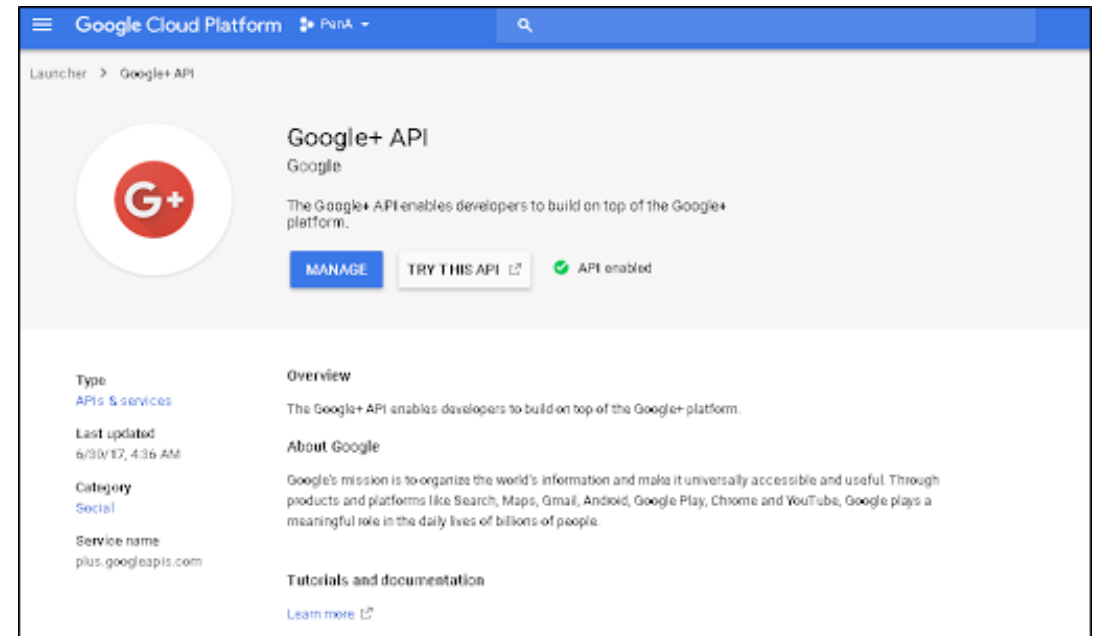

Gambar 9. Mengaktifkan Google+ Api pada project yang sudah dibuat.

\subsection{Listing Program}

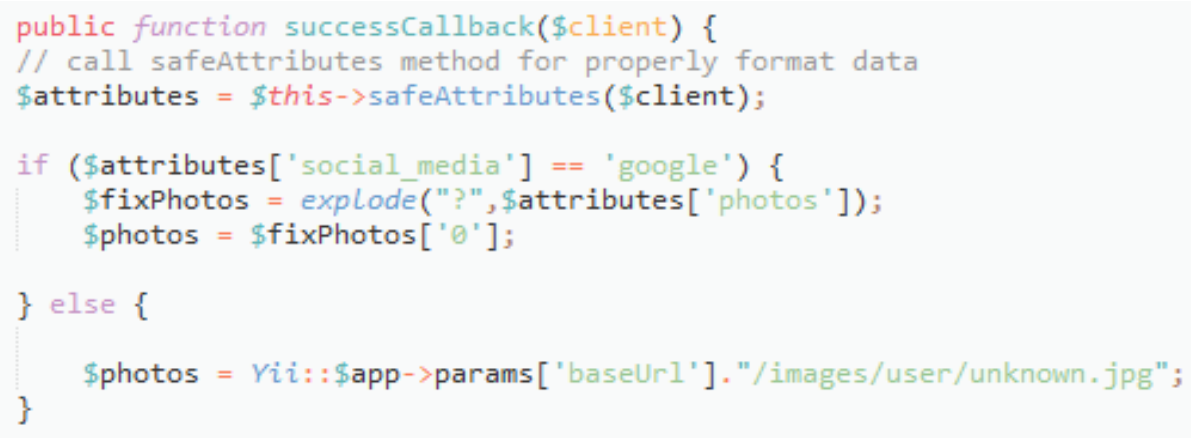

Gambar 10. Penyimpanan session sementara gambar dari Rinfo+

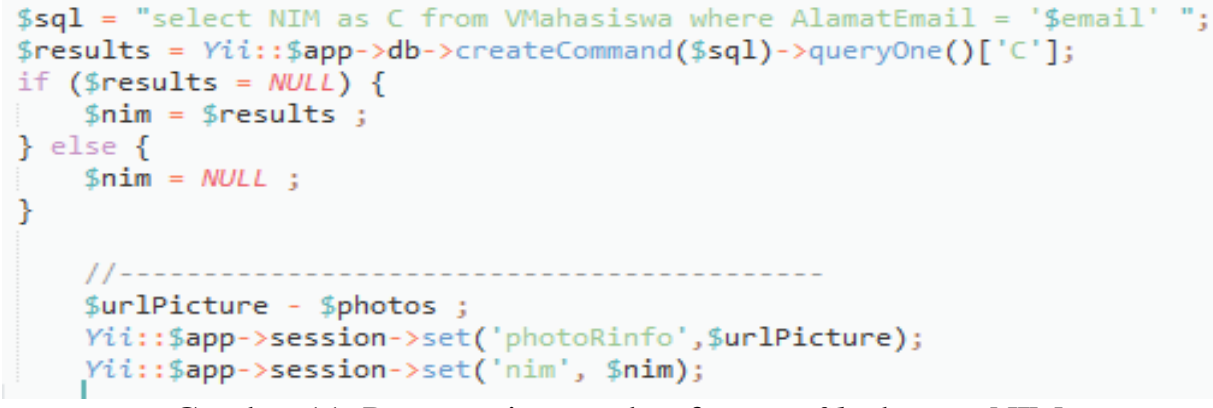

Gambar 11. Penyesuaian gambar foto profile dengan NIM.

Pada Script PHP di atas untuk menyesuaikan gambar foto profile dengan NIM (Nomor Induk Mahasiswa) yang sudah dibuat pada database user mahasiswa/Pribadi Raharja. Dalam hal ini foto profile yang disimpan sementara pada session ditampilkan pada header dan juga menu navigation bar. 


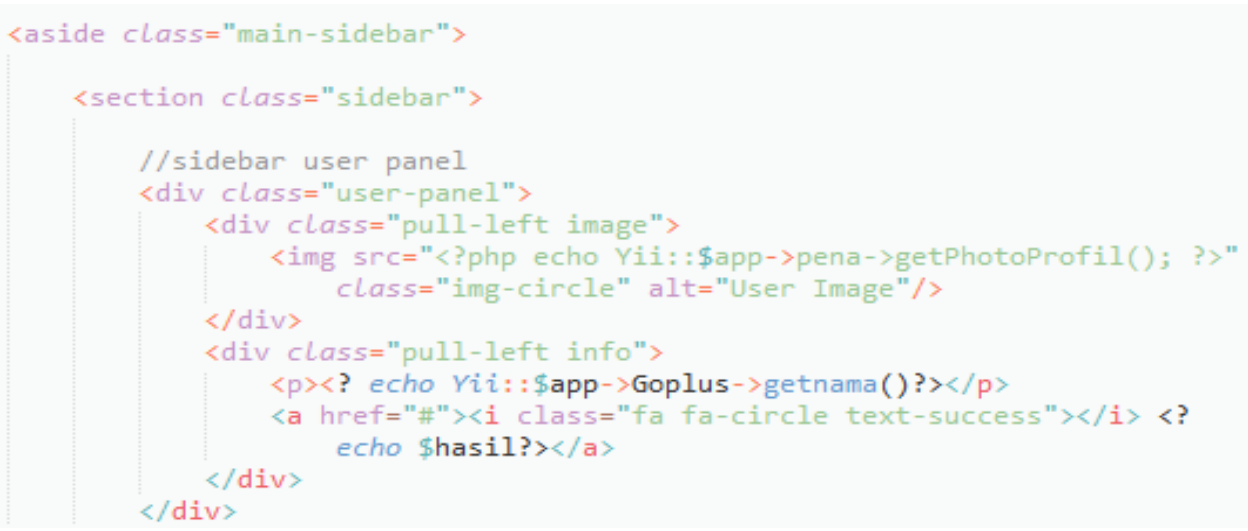

Gambar 12. Integrasi foto profile dari Rinfo+ Api dengan website PenA

Script PHP di atas yang digunakan untuk integrasi Rinfo+ Api dengan website PenA, di mana digunakan sebagai integrasi foto profile pada menu navigation bar agar mengetahui siapa saja yang login melalui foto profile yang telah disimpan pada session.

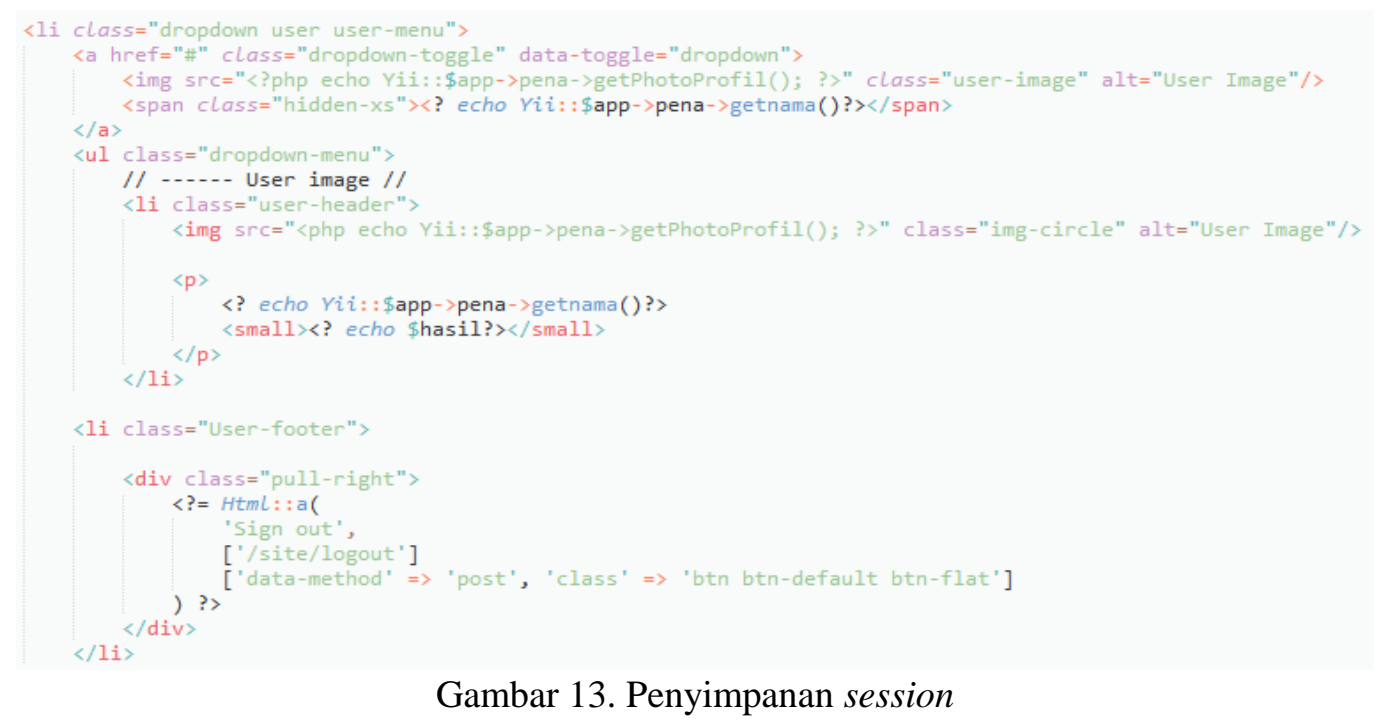

Dalam Script PHP di atas merupakan integrasi Rinfo+ pada website PenA (website berbasis yii framework) di mana foto profile yang tadi sudah disimpan pada session ditampilkan kembali pada bagian header.

\subsection{Implementasi}




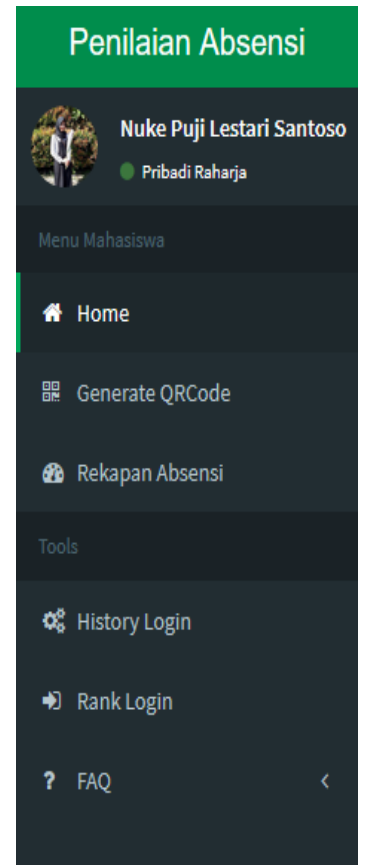

Gambar 14. Tampilan menu navigation bar PenA (Penilaian Absensi)

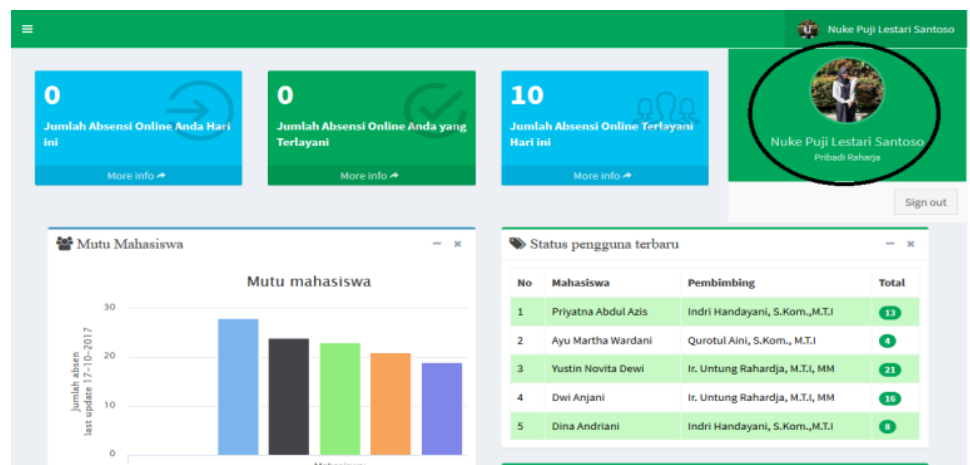

Gambar 15. Tampilan header pada home PenA (Penilaian Absensi)

Pada gambar 14 dan 15 menjelaskan bahwa halaman PenA (Penilaian Absensi) terdapat menu navigation bar dan header pada sistem PenA (Penilaian Absensi) yang sudah terintegrasi dengan Rinfo+ adanya foto profile sebagai identitas mahasiswa/Pribadi Raharja.

Dari hasil implementasi pada sistem PenA memberikan kemudahan bagi sisi dosen pembimbing karena terdapat foto profile mahasiswa pada sistem PenA (Penilaian Absensi) yang memudahkan dosen pembimbing mendapatkan informasi yang lebih akurat terhadap mahasiswa bimbingan. Kemudahan saat digunakan oleh user dengan mengunjungi website PenA yaitu http://pena.raharja.ac.id kemudian user dimudahkan dengan satu langkah mudah login menggunakan with Rinfo sistem PenA secara otomatis sudah terdapat identitas nama, status dan foto profile yang diintegrasikan dengan menggunakan Google Api. Selain itu, perancangan sistem PenA menggunakan Yii Framework guna memberikan tampilan sistem PenA yang lebih user friendly dan menarik.

\section{KESIMPULAN}

Terdapat 2 (dua) uraian permasalahan dan dapat diselesaikan menggunakan 5 (lima) langkah untuk integrasi antara PenA dan Rinfo, menghasilkan 5 (lima) kesimpulan yaitu: 
a. Rinfo+ atau Rinfo Plus adalah salah satu media yang dioperasikan oleh Google Inc dan juga aplikasi yang menggunakan platform google sebagai aplikasi untuk berbagi dan mendapatkan informasi bagi mahasiswa di Perguruan Tinggi Raharja yang disediakan oleh Rinfo. Dan PenA (Penilaian Absensi) adalah penilaian absensi secara online hanya dapat Login dengan email Rinfo sebagai Magic Key Pribadi Raharja (mahasiswa bimbingan).

b. Adanya admin Console yang bisa digunakan untuk Login SSO pada Pena berupa client secret, client id dan pengaktifan Rinfo+ api untuk menampilkan foto profile pada PenA.

c. Listing program pada view dan Controller guna integrasi foto profile Rinfo+ dengan PenA guna menampilkan foto profile mahasiswa bimbingan.

d. Informasi mahasiswa bimbingan lebih detail dan sesuai data pada Rinfo.

e. Secara visual pun lebih menarik yaitu terdapat foto profile mahasiswa bimbingan pada navigation bar dan header dalam home PenA setelah berhasil melakukan Login.

\section{SARAN}

Berdasarkan penjelasan di atas yang telah diuraikan sebelumnya oleh penulis dan dapat disimpulkan dari penjelasan tersebut, terdapat 2 (dua) saran antara lain :

a. Agar adanya foto mahasiswa dalam grafik yang sudah ada pada PenA (Penilaian Absensi) untuk mengetahui mahasiswa tersebut.

b. Pengembangan selanjutnya visual dari website PenA (Penilaian Absensi) lebih menarik lagi serta memudahkan bagi mahasiswa tersebut dalam menggunakan PenA (Penilaian Absensi).

\section{UCAPAN TERIMA KASIH}

Penulis mengucapkan terima kasih kepada Perguruan Tinggi Raharja yang telah memberi dukungan financial dan membantu memberikan saran terhadap penelitian ini.

\section{DAFTAR PUSTAKA}

[1] Rahardja, U., Aini, Q. and Khoirunisa, A., 2017. Implementasi Business Intelligence Menggunakan Highchart pada Sistem Penilaian Absensi berbasis YII Framework. CSRID (Computer Science Research and Its Development Journal), 9(2), pp.115-124.

[2] Rahardja, U., Tejosuwito, N.J. and Armansyah, F.S., 2017. PERANCANGAN APLIKASI PEN+ BERBASIS MOBILE UNTUK MEMUDAHKAN KINERJA DOSEN PADA PERGURUAN TINGGI. Technomedia Journal, 1(2), pp.51-62.

[3] Kuntoro, P.T., Untung, R. and Siti, C., 1978. Pengontrolan Mutu Sistem Informasi Dengan Metode Database Self Monitoring. CCIT Journal ISSN, 8282.

[4] Untung, R., Muhamad, Y. and Eva, R., Optimalisasi Key Performance Indicators (KPI) Melalui Pendekatan Balance Scorecard Upaya Mengimplementasikan Performance Management System (PMS) Pada Perguruan Tinggi. CCIT Journal ISSN, 6(2).

[5] Rahardja, U., Harahap, E.P. and Anjani, D., 2018. Pemanfaatan Rinfogroup Sebagai Media Diskusi dan Penilaian Keaktifan Mahasiswa. Sisfotenika, 8(1), pp.81-92.

[6] Rahardja, U., Tiara, K. and Wijaya, R.I.T., 2014. Penerapan Rinfo Sebagai Media Pendukung Untuk Proses Pembelajaran Pada Perguruan Tinggi Raharja. Jurnal CCIT, $8(1)$.

[7] Rizky. Cara Upload Sampul Paper Pada PESSTA+ Menggunakan Rinfo+. Retrieved from http://iran.ilearning.me/2016/03/02/cara-upload-sampul-paper-pada-pessta-menggunakanrinfo/ . (Diakses pada tanggal 24 Oktober 2017).

[8] Aini, Q., Graha, Y.I. and Zuliana, S.R., 2017. Penerapan Absensi QRCode Mahasiswa Bimbingan Belajar pada Website berbasis YII Framework. SISFOTENIKA, 7(2), pp.207218. 
[9] Rahardja, U., Fadillah, I. and Lestari, W., 2017, August. PENGGUNAAN SYSTEM SINGLE SIGN ON (SSO) DALAM MENDUKUNG KEMAJUANPADA FORUM RHJFOX DI PERGURUAN TINGGI RAHARJA. In SISITI: Seminar Ilmiah Sistem Informasi dan Teknologi Informasi (Vol. 5, No. 1).

[10] Amri, M.S., 2011. Membangun sistem navigasi di Surabaya menggunakan google maps API. Jurnal Teknik Informatika. Institut Teknologi Sepuluh November Surabaya. Surabaya.

[11] Google Inc., "Google+ API", online https://developers.google.com/+/web/api/rest/ . (Diakses pada tanggal 23 Oktober 2017)

[12] Han, J., Pei, J. and Kamber, M., 2011. Data mining: concepts and techniques. Elsevier.

[13] U, Rahardja., A. Moein., \& N. Lutfiani. (2017). Leadership, Competency, Working Motivation and Performance of High Private Education Lecturer with Institution Accreditation B: Area Kopertis IV Banten Provience. Man In India. 97 (24), 179-192

[14] Warsito, A.B.,Handayani, I. and Putri, N.E., INTEGRASI DATA KARYA ILMIAH PADA WEBSITE WIDURI. RAHARJA. INFO KE DALAM WEBSITE RAHARJA. AC. ID

[15] Junus, M., 2012. Sistem Pelacakan Posisi Kendaraan Dengan Teknologi GPS \& GPRS Berbasis Web. Jurnal Eltek, 10(02)

[16] Reza, N.F.F., 2013. Integrasi Teknologi Google Earth dan Flash dalam Penyajian Sistem Informasi Sekolah SMA dan SMK di Kota Salatiga (Doctoral dissertation, Program Studi Teknik Informatika FTI-UKSW).

[17] Atan, S.S. and Badusah, J., 2016. Aplikasi Rangkaian Sosial Google Plus dalam Pengajaran dan Pembelajaran Komponen Sastera. Jurnal Pendidikan Bahasa Melayu, 3(1), pp.31-41.

[18] Sumiari, N.K., 2016. Pemanfaatan Google API untuk Model Interoperability Web Berbasis PHP dengan Google Drive. Jurnal Sistem dan Informatika, 10(1).

[19] Untung, R., Suryo, G. and Valent, S., 1978. Access Restriction Sebagai Bentuk Pengamanan Dengan Metode IP Token. CCIT Journal ISSN, 8282.

[20] Aini, Q., Rahardja, U. and Allamiah, F., 2018. Perancangan Sistem Absensi Kinerja Pengabdian Tri Dharma secara Online pada Website Berbasis YII Framework. SISFOTENIKA, 8(1), pp.13-22.

[21] Pasaribu, J.S., 2017. PENERAPAN FRAMEWORK YII PADA PEMBANGUNAN SISTEM PPDB SMP BPPI BALEENDAH KABUPATEN BANDUNG. Jurnal Ilmiah Teknologi Informasi Terapan, 3(2).

[22] Warsito, A.B. and Yusup, M., 2014. Kajian Yii Framework dalam Pengembangan Website Perguruan Tinggi. CCIT Journal 3 (STMIK RAHARJA), 7(3), pp.437-451.

[23] Google Inc., "OAuth 2.0 for Client-side Web Applications ", online at https://developers.google.com/+/domains/authentication/ (Diakses pada tanggal 23 Oktober 2017).

[24] Aini, Q., Rahardja, U. and Naufal, R.S., 2018. Penerapan Single Sign On dengan Google pada Website berbasis YII Framework. SISFOTENIKA, 8(1), pp.57-68. 